\title{
Directional Electron Transfer Mechanisms with Graphene Quantum Dots as the Electron Donor for Photodecomposition of Perfluorooctane Sulfonate
}

Dahong Huang ${ }^{1}$, Lifeng Yin ${ }^{1}$, Xinyan $\mathrm{Lu}^{1}$, Shumin $\mathrm{Lin}^{1}$, Zhijuan Niu ${ }^{1}$, Junfeng Niu ${ }^{1,2 *}$

\footnotetext{
${ }^{1}$ State Key Laboratory of Water Environment Simulation, School of Environment, Beijing Normal University, Beijing 100875, P.R. China

${ }^{2}$ School of Environment and Civil Engineering, Dongguan University of Technology, Dongguan, Guangdong 523808, P.R. China
}

Dahong Huang, E-mail: huangdahong@mail.bnu.edu.cn

Lifeng Yin, E-mail: 1fyin@bnu.edu.cn

Xinyan Lu, E-mail: xinyanl@mail.bnu.edu.cn

Shumin Lin, E-mail: shuminlin@ mail.bnu.edu.cn

Zhijuan Niu, E-mail: niuzj@sohu.com

Junfeng Niu, E-mail: junfengn@ bnu.edu.cn

*Corresponding author: e-mail: junfengn@ bnu.edu.cn, phone: +86-10-5880 7612, fax: +86-10-5880
7612. 1 


\section{ABSTRACT}

Graphene quantum dots (GQDs) were synthesized via the oxygen-driven unzipping of graphene under ultra-high frequency ultrasonication, and then attached to the $\mathrm{SiC}$ nanoparticles by the hydrothermal method to form the SiC/GQDs nanocomposites. The SiC/GQDs exhibited superior photoactivity over the decomposition of perfluorooctane sulfonate $\left(\mathrm{C}_{8} \mathrm{~F}_{17} \mathrm{SO}_{3} \mathrm{H}\right.$, PFOS), which was even harder to decompose than perfluorooctanoic acid (PFOA). This work presented the first instance of employing photoexcited semiconductor nanomaterials to realize the improvement from the activation of the $-\mathrm{F}_{2} \mathrm{C}-\mathrm{COOH}$ bond in PFOA to the activation of $-\mathrm{F}_{2} \mathrm{C}-\mathrm{SO}_{3} \mathrm{H}$ in PFOS. The decomposition rate constants $(k)$ of $2-\mathrm{CF}_{3}-\mathrm{PFOS}, 6-\mathrm{CF}_{3}-\mathrm{PFOS}$ and linear-PFOS with SiC/GQDs were $0.127 \mathrm{~h}^{-1}, 0.115 \mathrm{~h}^{-1}, 0.098 \mathrm{~h}^{-1}$, and the corresponding half-lives were $5.5 \mathrm{~h}, 6.0 \mathrm{~h}, 7.1 \mathrm{~h}$, respectively. The ratio of $k$ (the branched isomers : the linear isomers) significantly reduced from the 967 times via vacuum ultraviolet (VUV) photolysis to the same order of magnitude in this work. The X-ray photoelectron spectroscopy (XPS) and ultraviolet photoelectron spectroscopy (UPS) were conducted to investigate the electronic properties of SiC/GQDs, revealing the centermost directional electron transfer process during the reaction. The photogenerated electron originated from the $\pi-\pi^{*}$ transition of the $\mathrm{C}=\mathrm{C}$ bond and the $\mathrm{n}-\pi^{*}$ transition of the $\mathrm{C}=\mathrm{O}$ bond under UV excitation, transferred to $\mathrm{SiC}$ nanoparticles due to the heterojunction structure of $\mathrm{SiC} / \mathrm{GQDs}$, and then further transferred to the accumulated PFOS on the surface of SiC/GQDs for the electron-withdrawing property of sulfonate group, leading to the critical activation of sulfonate group. The decomposition mechanisms of PFOS involved the ionic headgroup cleavage, hydrolysis, hydrodefluorination, and the C-C bond scission.

Keywords: Perfluorooctane Sulfonate (PFOS); Graphene quantum dots; Heterojunction; Electron transfer; Sulfonate activation; Hydrodefluorination 


\section{Introduction}

Perfluorooctane sulfonate $\left(\mathrm{C}_{\mathrm{n}} \mathrm{F}_{2 \mathrm{n}+1} \mathrm{SO}_{3} \mathrm{H}\right.$, PFOS $)$ has been regulated to limit future manufacturing by the United States Environmental Protection Agency (USEPA), while a limited set of existing uses (metal finishing, plating baths, and semiconductor etching) is excluded from the regulations because these uses are ongoing and alternative are not available [1]. The widespread uses have resulted in the global occurrence of PFOS and related derivatives either from direct use of PFOS, as well as from indirect sources like degradation of perfluorooctane sulfonate precursors

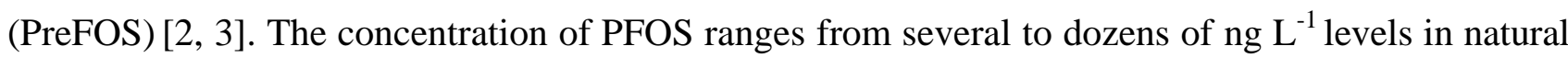
waters, and the concentration can be as high as $120 \mu \mathrm{g} \mathrm{L}^{-1}$ (ground water) and $2210 \mu \mathrm{g} \mathrm{L} \mathrm{L}^{-1}$ (surface water) in airports or other polluted areas [4-6]. PFOS has developmental toxicity, immunotoxicity, and hepatotoxicity and can be bio-accumulated in the human body and wildlife tissues, posing potential health risks $[7,8]$. PFOS was thus added as the persistent organic pollutants (POPs) to Annex B of the Stockholm Convention in 2009 [9]. To address the impending risks posed to the environment, the efficient and economical technologies for PFOS disposal have become a practical need particularly in the frame of global implementation of the Stockholm Convention.

Persistence of perfluoroalkyl compounds (PFCs) is mainly caused by their intrinsic bond strengths (C-F, $531.5 \mathrm{~kJ} \mathrm{~mol}^{-1}$ ) [10]. Compared with perfluorooctanoic acid (PFOA), PFOS is even more difficult to degrade for the presence of strong electron-withdrawing headgroup — sulfonate group $[11,12]$. PFOS is inert to many methods that can efficiently decompose PFOA, such as electrochemical oxidation with $\mathrm{Ti} / \mathrm{SnO}_{2}-\mathrm{Sb} / \mathrm{PbO}_{2}$ anode, photocatalysis with commercial nano- $\mathrm{TiO}_{2}$ (Degussa P25), and photolysis under UVC light. According to the previous researches, PFOS decomposition started with the cleavage of $-\mathrm{F}_{2} \mathrm{C}-\mathrm{SO}_{3} \mathrm{H}$ bond, thus the focus of PFOS decomposition was how to realize initial activation of sulfonate group [13, 14]. Sulfonate group in PFOS is 
recalcitrant to traditional advanced oxidation processes (AOPs), while the hydrated electron $\left(\mathrm{e}_{\mathrm{aq}}{ }^{-}\right)$ induced reduction has been recently demonstrated to be effective to activate the sulfonate group [15, 16]. However, due to the high reactivity of $\mathrm{e}_{\mathrm{aq}}{ }^{-}$with other coexistent oxidative species in solution, a large amount of chemical agent (molar concentration, $\mathrm{I}^{-}: \mathrm{PFOS}=500: 1$ ) that can promote the $\mathrm{e}_{\mathrm{aq}}{ }^{-}$ production was necessary to ensure fast decomposition kinetics [16]. Inspired by these researches, conduction band electron $\left(\mathrm{e}_{\mathrm{cb}}{ }^{-}\right)$generated by light irradiation with strong reduction ability as well, can probably substitute for $\mathrm{e}_{\mathrm{aq}}{ }^{-}$to activate the sulfonate group. Moreover, different from the free diffusion of $\mathrm{e}_{\mathrm{aq}}{ }^{-}$during the reaction, photogenerated $\mathrm{e}_{\mathrm{cb}}{ }^{-}$can directionally transfer to the electron acceptor - PFOS, which is accumulated on the surface of hydrophobic nanomaterials as the surfactant. This process provides the possibility to activate sulfonate group via directional electron transfer, reducing the transfer distance of electron and minimizing the competitive reaction to further increase the proportion of electron participates in the reaction and optimize the decomposition of PFOS.

To the best of our knowledge, there is still no report on the PFOS decomposition with photoactivated semiconductor nanomaterials, that can realize the cleavage of $-\mathrm{F}_{2} \mathrm{C}-\mathrm{SO}_{3} \mathrm{H}$ bond via the sulfonate activation under UV excitation. In our previous work, it was demonstrated that photoinduced generation of the $\mathrm{Si}-\mathrm{H}$ bond on the metal-free $\mathrm{SiC}$ nanoparticle can efficiently decompose perfluorooctanoic acid (PFOA) via the $\mathrm{Si}-\mathrm{H} / \mathrm{C}-\mathrm{F}$ redistribution (conversion into Si-F/C-H) [17]. Considering the analogous molecule structures of perfluoroalkyl radical $\left(\mathrm{C}_{\mathrm{n}} \mathrm{F}_{2 \mathrm{n}+1^{\bullet}}\right)$ after the headgroup cleavages of PFOA and PFOS, new questions are thus proposed based on the that work: can $\mathrm{SiC}$ provide sufficient photogenerated electron to activate the sulfonate group in PFOS, can the $\mathrm{C}_{\mathrm{n}} \mathrm{F}_{2 \mathrm{n}+1}$ in PFOS react with $\mathrm{SiC}$ in the similar way to realize the subsequent PFOS decomposition, and will the decomposition efficiency be further improved by introducing other 
co-catalysts?

Quantum dots (e.g., CdS, CdSe, PbS), as the typical zero-dimensional nanomaterial, possess high reactivity for the large ratio of surface atoms and have been well demonstrated to effectively improve the photoelectrical and photochemical properties of semiconductor materials as the co-catalyst [18-20]. However, their large-scale applications are heavily impeded by the potential environmental hazard for the release of heavy-metal ions. Graphene quantum dots (GQDs) have attracted considerable attention nowadays for the excellent properties, such as low toxicity, low cost, chemical inertia, and biocompatibility [21, 22]. It is still unknown whether GQDs can work as the suitable co-catalyst to promote the decomposition of PFOS.

The objective of this work was to investigate the decomposition mechanisms of PFOS under UV light irradiation with as-synthesized SiC/GQDs nanocomposites. The decomposition kinetics of branched and linear PFOS isomers under different conditions (with SiC/GQDs, with SiC, direct photolysis) was investigated. The transformation of PFOS was inferred based on the qualitative and quantitative analyses of intermediates, and the mass balance of fluorine and sulfur elements. The mechanisms responsible for PFOS decomposition were further discussed by elaborating the electron transfer process, with the aid of optical properties and electronic structure analyses of SiC/GQDs.

\section{Materials and methods}

\subsection{Reagents and Materials}

Silicon carbide (SiC, 99.9\%) was obtained from Sigma-Aldrich Chemicals in Saint Louis, USA. Potassium perfluorooctane sulfonate $\left(\mathrm{C}_{8} \mathrm{~F}_{17} \mathrm{SO}_{3} \mathrm{~K}, 98 \%\right)$ was purchased from Matrix Scientific in Columbia, USA. Graphene nanoplatelets (Graphene, 99.9\%) were purchased from Strem Chemicals in Newburyport, USA. Potassium iodide (KI, 99\%), isopropyl, ethanol, acetic acid, concentrated sulfuric acid, concentrated nitric acid and ammonia solution were supplied by Sinopharm in Beijing, 
CHN. All chemicals used in the experiments were the analytical grade or higher, and were used as received without further purification. Solutions were prepared with ultrapure/deionized water throughout the experiments by Milli-Q purification system.

\subsection{Synthesis of GQDs and $\mathrm{SiC} / G Q D$ s}

One hundred mg graphene was dispersed in concentrated nitric acid $(60 \mathrm{~mL})$ and sulfuric acid (20 mL), fully oxidized and unzipped by ultra-high frequency ultrasonication $(800 \mathrm{kHz}, 350 \mathrm{~W})$ for $30 \mathrm{~h}$. Then the mixture was diluted with deionized water $(200 \mathrm{~mL})$ and centrifuged to remove any impurities. The purified mixture was re-dispersed in deionized water (40 mL) and ammonia solution

$\left(5 \mathrm{~mL}, 13.80 \mathrm{~mol} \mathrm{~L}^{-1}\right)$, and then sealed in Teflon container at $110{ }^{\circ} \mathrm{C}$ for $4 \mathrm{~h}$. Finally, the resulting light yellow solution was further dialyzed by dialysis bag (retained molecular weight: $3500 \mathrm{Da}$ ). The concentration of GQDs solution was determined to be $\sim 80 \mathrm{mg} \mathrm{L}^{-1}$ by total organic carbon (TOC) analysis.

Five hundred $\mathrm{mg}$ of $\mathrm{SiC}$ was dispersed in $6.25 \mathrm{~mL}$ GQDs solution and $23.75 \mathrm{~mL}$ deionized water. After ultrasonication for $50 \mathrm{~min}$, the mixture was transferred into Teflon container at $140{ }^{\circ} \mathrm{C}$ for $5 \mathrm{~h}$. Then the samples were separated by centrifugation and washed five times with ethanol and deionized water to remove any impurities. The $\mathrm{SiC} / \mathrm{GQD}$ nanocomposites were finally vacuum freeze dried at $-60{ }^{\circ} \mathrm{C}$ and stored for the following experiments.

\subsection{Characterization}

Photoluminescence (PL) spectrum was carried out on a spectrometer (TemPro-01, Horiba Jobin Yvon; Paris, FRA), the excitation wavelength and the corresponding emission wavelength were 250-370 $\mathrm{nm}$ and 360-480 $\mathrm{nm}$, respectively. UV-vis absorption spectrum was recorded on a spectrophotometer (DR 6000, Hach; Loveland, USA) in the wavelength range from $200 \mathrm{~nm}$ to 500 nm. 
X-ray photoelectron spectroscopy (XPS) spectra data was measured by an XPS system (ESCALAB 250Xi, ThermoFisher; Waltham, USA) with the monochromatic Al Ka radiation (1486.6 eV). Survey analysis in the whole range of X-ray spectra and high-resolution analyses in the typical zone of C-1s, O-1s, Si-2p were performed. Ultraviolet photoelectron spectroscopy (UPS) was conducted using a UPS system (ESCALAB 250Xi, ThermoFisher; Waltham, USA) with the He(I) resonance $584 \AA$ radiation of $21.217 \mathrm{eV}$ for the valence band (VB) energy region measurements.

The SiC/GQDs nanocomposites were characterized by high-resolution transmission electron microscopy (HRTEM) to investigate the physical structures, detecting the lattice parameter of SiC/GQDs. HRTEM images were obtained by a transmission electron microscope (Tecnai TF-20, Philips; Eindhoven, NED) operated at an accelerating voltage of $200 \mathrm{kV}$. Samples for HRTEM images were prepared by dispersing the SiC/GQDs ethanol solution on ultra-thin holey carbon film and dried at room temperature $\left(25 \pm 1{ }^{\circ} \mathrm{C}\right)$. X-ray powder diffraction (XRD) was conducted to investigate the phase structures. XRD measurement was performed on an X'Pert Pro MPD (PANalytical; Almelo, NED) with $\mathrm{Cu} \mathrm{K \alpha}$ radiation $\left(\lambda=1.5418 \AA\right.$ ), and the scan rate was $5^{\circ} \min ^{-1}$ within the $2 \theta$ range $\left(20^{\circ}\right.$ to $\left.80^{\circ}\right)$. Total organic carbon (TOC) concentration of GQDs was analyzed by TOC machine (TOC-LCPH, SHIMADZU; Kyoto, JPN) according to the $680{ }^{\circ} \mathrm{C}$ combustion catalytic oxidation method.

\subsection{Decomposition Procedures}

The heterogeneous decomposition of PFOS was conducted in a cylindrical reactor (volume, 80 $\mathrm{mL}$; diameter, $50 \mathrm{~mm}$; height, $120 \mathrm{~mm}$ ) equipped with a $254 \mathrm{~nm} \mathrm{UV}$ lamp (5 W, Cnlight; Guangdong, CHN) as irradiation source in all laboratory batch experiments. UV lamp was placed inside the reactor with a quartz tube as waterproof (diameter, $26 \mathrm{~mm}$; height, $110 \mathrm{~mm}$ ), and the thickness of solution was $12 \mathrm{~mm}$, reducing the loss of light energy during the photon transfer process. 
The concentration of PFOS solution was $0.019 \mathrm{mmol} \mathrm{L}^{-1}$ throughout the whole work. The solution was stirred for $0.5 \mathrm{~h}$ in darkness to ensure the establishment of an adsorption-desorption equilibrium of the suspension composed of PFOS solution and $40 \mathrm{mg}$ SiC/GQDs nanocomposites. The decomposition experiment was performed under stirring at the speed of $800 \mathrm{r} \mathrm{min}^{-1}$, ensuring the well dispersion of SiC/GQDs. Preliminary experiments indicated that there was no further adsorption of PFOS on SiC/GQDs after $0.5 \mathrm{~h}$. The experiments were carried out for $20 \mathrm{~h}$ duration to evaluate the activity of SiC/GQDs nanocomposites for PFOS decomposition. In order to avoid the evaporation of aqueous solution caused by long-term illumination, the parafilm was used to seal the reaction system. Samples were collected at intervals for triple-stage quadrupole mass spectrometry (TQ-MS/MS) analyses: typically, at $0 \mathrm{~h}$ (the dynamic adsorption-desorption equilibrium), $4 \mathrm{~h}, 8 \mathrm{~h}$, $12 \mathrm{~h}, 16 \mathrm{~h}$ and $20 \mathrm{~h}$. The sampling volume was $0.5 \mathrm{~mL}$, and the total sampling volume was $3 \mathrm{~mL}$, $3.75 \%$ of the initial volume. Taking samples thus slightly affected the concentration of PFOS. Each sample was filtered through a polycarbonate membrane $(0.45 \mu \mathrm{m})$ to separate SiC/GQDs powder from the suspension. The control experiments suggested that the adsorption by ultrafilter was negligible, nor the evaporation during the decomposition process.

The concentration of PFOS and identification of intermediate products were analyzed by a TQ-MS/MS (API 3200, Applied Biosystems; Foster, USA) operating in negative electrospray mode. Multiple reaction monitoring (MRM) experiments were performed with a gradient mobile phase which was composed of solvent A (methanol) and solvent $\mathrm{B}\left(5 \mathrm{mmol} \mathrm{L} \mathrm{L}^{-1}\right.$ ammonium acetate): 0 5.0 min, methanol gradient increased from $70 \%$ to $95 \% ; 5.0-8.0$ min, held solvent $\mathrm{A}$ at $95 \% ; 8.0-$ 8.1 min, linear decrease of solvent A from $95 \%$ to $70 \% ; 8.1-13.0$ min, held this proportion.

The concentrations of fluoride ion $\left(\mathrm{F}^{-}\right)$, sulfonate ion $\left(\mathrm{SO}_{4}{ }^{2-}\right)$ in aqueous solution were determined by an ion-chromatograph system (ICS-1100, Dionex; Sunnyvale, USA). The system was 
equipped with the separation column (Dionex IonPac AS 12A, $4 \mathrm{~mm} \times 200 \mathrm{~mm}$ ) operating at $30{ }^{\circ} \mathrm{C}$. The mobile phase was $20 \mathrm{mmol} \mathrm{L}^{-1} \mathrm{KOH}$, and the flow rate was set at $1.0 \mathrm{~mL} \mathrm{~min}^{-1}$.

\section{Results and discussion}

\subsection{PFOS Decomposition Kinetics}

The results of PFOS decomposition under various conditions are exhibited in Figure 1. The ${ }^{19} \mathrm{~F}$ nuclear magnetic resonance (NMR) spectra results of technical-PFOS by $\left(\mathrm{CF}_{2}\right.$ region) are shown in Figure S1, containing linear-PFOS, 2- $\mathrm{CF}_{3}-\mathrm{PFOS}$, and $6-\mathrm{CF}_{3}-\mathrm{PFOS}$ isomers. Neither direct photolysis nor addition of SiC under $254 \mathrm{~nm}$ UV irradiation decomposed technical-PFOS. While the SiC/GQDs efficiently decomposed both the branched and linear isomers, and the decomposition process well followed the pseudo-first-order reaction kinetics. The decomposition rate constants $(k)$ for 2- $\mathrm{CF}_{3}$-PFOS, 6-CF $-\mathrm{PFOS}$ and linear-PFOS were $0.127 \mathrm{~h}^{-1}\left(R^{2}=0.98\right), 0.115 \mathrm{~h}^{-1}\left(R^{2}=0.99\right)$, $0.098 \mathrm{~h}^{-1}\left(R^{2}=0.99\right)$, and the corresponding half-life periods were $5.5 \mathrm{~h}, 6.0 \mathrm{~h}, 7.1 \mathrm{~h}$, respectively. What deserved attention, decomposition rates for the branched isomers and the linear isomer were of the same order of magnitude. In the published papers, however, the branched isomers decomposed much more quickly than the linear isomer (direct VUV photolysis, the degradation rate of branched isomers is 967 times as fast as that of linear isomers; vitamin $\mathrm{B}_{12}$ reduction, only applicable for the branched isomers and inert to the linear isomers) [23, 24]. This significant difference in experimental phenomenon should be attributed to the different decomposition mechanisms that would be discussed in detail later. After all, the SiC/GQDs was proved to be effective for decomposition of technical-PFOS.

\section{Figure 1 and Table 1 here}




\subsection{Intermediate Analyses of PFOS}

MRM results of intermediates are exhibited in Figure 2, that was detected by TQ-MS/MS to explore the PFOS decomposition process. A series of short-chain perfluorocarboxylic acids (PFCAs) including $\mathrm{C}_{3} \mathrm{~F}_{7} \mathrm{COO}^{-}$(PFBA), $\mathrm{C}_{4} \mathrm{~F}_{9} \mathrm{COO}^{-}(\mathrm{PFPeA}), \mathrm{C}_{5} \mathrm{~F}_{11} \mathrm{COO}^{-}$(PFHxA), $\mathrm{C}_{6} \mathrm{~F}_{13} \mathrm{COO}^{-}$(PFHpA) and $\mathrm{C}_{7} \mathrm{~F}_{15} \mathrm{COO}^{-}$(PFOA), were detected during the decomposition process at 1.99, 2.36, 2.95, 3.76, 4.64 min, respectively. None of short-chain PFCAs was detected at the beginning of the reaction $(0 \mathrm{~h})$, and the concentrations of those intermediates were time-dependent during the reaction. With the increase of reaction time, the concentrations of PFOA, PFHpA and PFHxA increased to the peak $\left(0.25 \mu \mathrm{mol} \mathrm{L}{ }^{-1}, 0.32 \mu \mathrm{mol} \mathrm{L}-1\right.$ and $0.80 \mu \mathrm{mol} \mathrm{L}{ }^{-1}$, respectively) at $16 \mathrm{~h}$, and the concentrations of PFPeA and PFBA increased continuously $\left(0.67 \mu \mathrm{mol} \mathrm{L}^{-1}\right.$ and $1.23 \mu \mathrm{mol} \mathrm{L}{ }^{-1}$ after $20 \mathrm{~h}$, respectively) throughout the whole decomposition process. These observations demonstrated that short-chain PFCAs was probably formed through a stepwise C-C bond scission during the PFOS decomposition.

\section{Figure 2 here}

\subsection{Mass Balance of Sulfur and Fluorine Elements}

To further analyze PFOS decomposition process, the mass balance of sulfur and fluorine elements were investigated in this work. The concentrations of $\mathrm{F}^{-}$and $\mathrm{SO}_{4}{ }^{2-}$ in the solution were zeroed at $0 \mathrm{~h}$ to avoid the influence of original impurity in technical-PFOS. The contents of three main isomers in technical-PFOS from Matrix Scientific were as follows: linear-PFOS, 62.3\% ; 2- $\mathrm{CF}_{3}$-PFOS, $22.0 \% ; 6-\mathrm{CF}_{3}$-PFOS ,11.4\% [25]. The mass balance of sulfur was $78.8 \% \pm 6.6$ for the $\mathrm{SO}_{4}{ }^{2-}$ in solution, and $10.1 \% \pm 3.4$ for the sulfonate group in undecomposed PFOS. The mass 
balance of fluorine was $22.6 \% \pm 4.0,9.3 \% \pm 4.2$ and $10.1 \% \pm 3.4$ for the $\mathrm{F}^{-}$in solution, the fluorine in short-chain PFCAs and undecomposed PFOS, respectively. The mass balance of sulfur exhibited a high recovery rate (up to $\sim 88.9 \%$ ). As for fluorine element, it was obviously that there was $\sim 58.0 \%$ fluorine element unrecovered. The control experiment was performed by addition of HF solution into the reactor, and there was no notable decrease of $\mathrm{F}^{-}$concentration after 7 days, suggesting $\mathrm{F}^{-}$ hardly adsorbed to the inner wall of the reactor. Where was the rest fluorine element? To answer this question, we conducted the XPS analyses of SiC/GQDs (collected before and after the decomposition), as shown in Figure S2. There was significant fluorination on the surface of SiC/GQDs, it was similar to the result we reported in the PFOA decomposition. The $\mathrm{F}^{-}$detected in solution can be thus ascribed to the hydrolysis process of intermediates, and the unrecovered fluorine element probably mainly composed of the $\mathrm{Si}-\mathrm{F}$ bond that generated during the hydrodefluorination of short-chain PFCAs [17].

\section{Figure 3 here}

Based on the analyses of intermediates and mass balance, we can demonstrate that decomposition of PFOS included hydrolysis and hydrodefluorination, which we have already well proved in the previous work. Then why $\mathrm{SiC}$ was not feasible in this reaction system and how the introduce of GQDs changed the decomposition process, that still needs the further experiment.

\subsection{The Optical and Electronic Properties of SiC/GQDs}

To elucidate the effect of GQDs in the reaction, it was of vital importance to investigate the physical, optical and electronic properties of the prepared GQDs. Characterization of the as-synthesized $\mathrm{SiC} / \mathrm{GQDs}$ nanocomposites by high-resolution transmission electron microscopy 
(HRTEM) showed the highly uniform dispersion of GQDs (1.8 to $3.6 \mathrm{~nm}$ in diameter) embedded onto the SiC nanoparticles (Figure S3). UV-vis absorption and fluorescence emission-excitation spectrum are shown in Figure 4. GQDs presented two typical absorption peaks at $310 \mathrm{~nm}$ and 340 nm from Figure 4a, which corresponded to the intrinsic peaks (Peak A and Peak C) of the PL excitation (PLE) in fluorescence emission-excitation map. As shown in Figure 4a, the absorption peak at $310 \mathrm{~nm}$ can be assigned to the $\pi-\pi^{*}$ transition of aromatic $\mathrm{sp}^{2}$-hybridized domains $\left(\pi^{*}\right.$ stands for the antibonding orbital of $\pi$ orbital), and the peak at $340 \mathrm{~nm}$ can be attributed to the $n-\pi^{*}$ transition of the surface oxygen defect (n stands for the oxygen nonbonding orbital) [26, 27]. Moreover, with the excitation wavelength increased from $250 \mathrm{~nm}$ to $370 \mathrm{~nm}$, the relative PL peak shifted to longer wavelengths in the range of $360 \mathrm{~nm}$ to $480 \mathrm{~nm}$. The GQDs exhibited the excitation-wavelength-dependent PL behavior, which was caused by the presence of defect states (composed of oxygen-containing functional groups) [28]. According to the above analyses, we can demonstrate the n orbital in HOMOs of GQDs, which was probably generated by the oxygen-driven unzipping of graphene.

As shown in figure $4 \mathrm{~b}$, two electronic transitions of $260 \mathrm{~nm}(4.77 \mathrm{eV}$, Peak A) and $310 \mathrm{~nm}$ (4.00 eV, Peak B) were observed in PLE spectrum, those can be regarded as the transitions of electrons from the $\sigma$ and $\pi$ orbitals (in highest occupied molecular orbitals, HOMOs) to the lowest unoccupied molecular orbitals (LUMOs) [29]. This phenomenon probably originated from zigzag edges of the GQDs periphery, related to the carbene-like triplet ground-state multiplicity $\left(\sigma^{1} \pi^{1}, \sigma^{2}\right)$ [30]. The calculated energy difference $(\delta E)$ of GQDs between the $\sigma$ and $\pi$ orbitals was $0.77 \mathrm{eV}$. In previous research, methylene was taken as the example to estimate the $\delta E$ between these two orbitals, the maximum $\delta E$ for a triplet ground state should be no more than $1.5 \mathrm{eV}$ [31]. That was in accordance with our results, suggesting the assignment of these two transitions was reasonable. 
From these optical properties analyses of GQDs, we can demonstrate the possible transitions of photogenerated electron in GQDs from the $\sigma, \pi$ and $\mathrm{n}$ orbitals in HOMOs to LUMOs under $254 \mathrm{~nm}$ UV excitation.

\section{Figure 4 here}

High-resolution XPS spectrum was performed to analyze the electronic structure of SiC/GQDs. The typical C-1s spectrum (Figure 5a) exhibited four distinct peaks located at $282.8 \mathrm{eV}, 284.8 \mathrm{eV}$, $286.0 \mathrm{eV}$ and $288.8 \mathrm{eV}$, corresponding to the $\mathrm{Si}-\mathrm{C}, \mathrm{C}=\mathrm{C}$ (aromatic $\mathrm{sp}^{2}$-hybridized carbon), C-O (hydroxyl groups) and $\mathrm{C}=\mathrm{O}$ (carbonyl groups) bond, respectively [32, 33]. The O-1s spectrum (see Figure S4 of the SI) can be resolved into two components at $531.2 \mathrm{eV}$ and $533.5 \mathrm{eV}$, which were associated with the $\mathrm{C}-\mathrm{O}$ and $\mathrm{C}=\mathrm{O}$ bonds, respectively [34]. Those specific oxygen-containing functional groups on the surfaces can make GQDs stable to attach to the $\mathrm{SiC}$ nanoparticle surfaces [35]. The two absorption peaks observed in Figure 5 can be attributed to the transitions of $\mathrm{C}=\mathrm{C}$ and $\mathrm{C}=\mathrm{O}$ bonds [36]. However, compared with the previous work, the peak at $\sim 290.1 \mathrm{eV}$, which corresponded to $\mathrm{C}=\mathrm{O}-\mathrm{OH}$ groups was not observed, the probable reason was that these carboxyl groups were efficiently reduced by ammonia in the hydrothermal process [34]. According to the XPS results, it can be further inferred that the transitions of photogenerated electron inside GQDs were mainly attributed to the $\pi-\pi^{*}$ transition of the $\mathrm{C}=\mathrm{C}$ bond and the $n-\pi^{*}$ transition of the $\mathrm{C}=\mathrm{O}$ bond.

Aside from the efficient electron transitions of GQDs, the proper conduction band level of $\mathrm{SiC} / \mathrm{GQDs}$ is also important to offer strong reductive $\mathrm{e}_{\mathrm{cb}}{ }^{-}$to lead to activation of sulfonate group. Ultraviolet photoelectron spectroscopy (UPS) was thus performed to determine the ionization 
potential (equivalent to the valence band energy $(E v)$ ) of $\mathrm{SiC}$ and $\mathrm{SiC} / \mathrm{GQD}$ nanocomposites [37]. The $E v$ of $\mathrm{SiC} / \mathrm{GQD}$ nanocomposites and $n$-type $\mathrm{SiC}$ were calculated to be -4.77 and $-5.83 \mathrm{eV}$ (vs. Vacuum) by subtracting the width of the He I UPS spectra (Figure 5b) from the excitation energy (21.22 eV). Considering the band gap (Eg) value (3.00 eV for both $\mathrm{SiC}$ and $\mathrm{SiC} / \mathrm{GQDs})$ determined from Figure S5, the conduction band energy $(E c)$ of SiC/GQDs nanocomposites and SiC were thus estimated to be -1.77 and $-2.83 \mathrm{eV}$ from $E v-E g$, respectively. The UPS results demonstrated that addition of GQDs significantly improved the $E c$ and $E v$ of $\mathrm{SiC} / \mathrm{GQD}$ compared with SiC. Based on the above results, we proposed that the quantum confinement effect led to a discrete energy level distributions of GQDs, and the formed HOMOs and LUMOs are higher than the corresponding $E v$ and $E c$ of $\mathrm{SiC}$, respectively. The previous research performed density functional theory (DFT) to calculate the theoretical HOMO $(-5.66 \mathrm{eV})$ and LUMO $(-0.68 \mathrm{eV})$ of GQDs, which was in accordance with our experimental results [38]. The heterojunction structure can be thus formed in SiC/GQDs due to the energy level matching, and it can efficiently improve the photoactivity by suppressing the recombination of the photogenerated carriers.

\section{Figure 5 here}

The photogenerated electrons originated from the $\pi-\pi^{*}$ transition of the $C=C$ bond and the $n-\pi^{*}$ transition of the $\mathrm{C}=\mathrm{O}$ bond, and then transferred from the LUMOs of GQDs to the conduction band (CB) of $\mathrm{SiC}$ nanoparticles, the photogenerated holes transferred from the valence band (VB) of SiC to the HOMOs of GQDs, improving the separation efficiency of the photogenerated carriers remarkably. What's more, a short electron pathway between the GQDs interior and the surface due to the quantum size can enhance the electron transfer as well [39]. GQDs acted as the electron 
donors in this process, in which electrons can be easily transferred to the surface of $\mathrm{SiC}$ nanoparticles. And then PFOS, which accumulated on the surface of SiC due to the surface-active properties, would act as the final electron acceptor for the electron-withdrawing property of sulfonate group. This electron transfer process can lead to the ionic headgroup cleavage (the sulfonate group) from PFOS, forming the perfluoroalkyl radicals $\left(\mathrm{C}_{8} \mathrm{~F}_{17}\right)^{\bullet}$. The initial directional electron transfer process was thus of great importance to the PFOS decomposition. SiC can hardly offer sufficient $\mathrm{e}_{\mathrm{cb}}{ }^{-}$to activate the sulfonate group without GQDs as the electron donor, that was probably the reason why SiC/GQDs is feasible for PFOS decomposition instead of SiC.

\subsection{Decomposition Mechanisms of PFOS}

Based on the above experimental results, the mechanisms for the photochemical transformation of PFOS in the presence of SiC/GQDs under UV irradiation is proposed in Figure 6. The electron was generated by the UV excitation of SiC/GQDs, and then decomposition of initial PFOS started with the electron transfer process. As soon as PFOS gained the electrons, the electron-mediated reduction occurred at the chain-terminal sulfonate group. One of the original $\mathrm{S}=\mathrm{O}$ bonds transformed into the $\mathrm{S}-\mathrm{O}$ bond, forming one unpaired electron on the $\mathrm{S}$ atom and one $\mathrm{O}^{-}$ion with the outer layer filled with eight electrons $\left(\mathrm{PFOS}^{\circ-}\right) . \mathrm{PFOS}^{\cdot 2-}$ inclined to react with $\mathrm{H}^{+}$, leading to the loss of $\mathrm{OH}^{-}$and yielding $\mathrm{C}_{\mathrm{n}} \mathrm{F}_{2 \mathrm{n}+1} \mathrm{SO}_{2}{ }^{\cdot} \cdot \mathrm{C}_{\mathrm{n}} \mathrm{F}_{2 \mathrm{n}+1} \mathrm{SO}_{2}{ }^{\bullet}$ subsequently dissociated into $\mathrm{C}_{\mathrm{n}} \mathrm{F}_{2 \mathrm{n}+1} \bullet$ and $\mathrm{SO}_{2}$ [11]. Since $\mathrm{SO}_{2}$ was easily dissolved into the solution, and the reaction system was sealed with parafilm, most of the generated $\mathrm{SO}_{2}$ transformed into $\mathrm{SO}_{4}{ }^{2-}$ and was detected by the ion-chromatograph. As for $\mathrm{C}_{n} \mathrm{~F}_{2 n+1}$, it can react with $\mathrm{H}_{2} \mathrm{O}$ to form the unstable $\mathrm{C}_{n} \mathrm{~F}_{2 n+1} \mathrm{OH}$, then $\mathrm{C}_{\mathrm{n}} \mathrm{F}_{2 \mathrm{n}+1} \mathrm{OH}$ converted into $\mathrm{C}_{\mathrm{n}-1} \mathrm{~F}_{2 \mathrm{n}-1} \mathrm{COF}$ by intramolecular rearrangement, and subsequently transformed into the short-chain PFCAs via hydrolysis [40]. In this way, $\mathrm{F}^{-}$was generated during the hydrolysis process. While based on the low concentration of $\mathrm{F}^{-}$detected in the solution, it was 
obviously that this hydrolysis is not the main pathway for $\mathrm{C}_{\mathrm{n}} \mathrm{F}_{2 \mathrm{n}+1} \bullet$ decomposition. On the other hand, the fluorine atoms at the chain-terminal of $\mathrm{C}_{\mathrm{n}} \mathrm{F}_{2 \mathrm{n}+1}$ e were gradually replaced by hydrogen atoms due to the nucleophilic substitution hydrodefluorination, the C-F bonds transformed into C-H bonds via the $\mathrm{Si}-\mathrm{H} / \mathrm{C}-\mathrm{F}$ redistribution (conversion into $\mathrm{C}-\mathrm{H}$ ) [17]. The generated $\mathrm{Si}-\mathrm{F}$ bonds were well demonstrated by the surface fluorination of $\mathrm{SiC}$ based on the XPS results. After all fluorine atoms at the chain-termination were replaced through the sequential $\mathrm{F} / \mathrm{H}$ exchange, the $\mathrm{CH}_{2}$ carbene was eliminated via the C-C scission due to the UV light excitation [17]. The generated short-chain PFCAs were detected by the TQ-MS/MS results for the qualitative and quantitative analysis, demonstrating this $\mathrm{C}-\mathrm{C}$ scission. It is thus concluded that $\mathrm{C}_{\mathrm{n}} \mathrm{F}_{2 \mathrm{n}+1}$ e was decomposed via the hydrodefluorination and hydrolysis process, the hydrodefluorination should be the main pathway for $\mathrm{C}_{\mathrm{n}} \mathrm{F}_{2 \mathrm{n}+1} \bullet$ decomposition.

\section{Figure 6 here}

According to previous research on VUV photolysis and $\mathrm{UV} / \mathrm{SO}_{3}{ }^{2-}$, the branched PFOS decomposed much faster than the linear isomers $[15,22]$. It was because that photon and $\mathrm{e}_{\mathrm{aq}}{ }^{-}$ directly reacted with PFOS molecule in solution, and the C-F bond in branched isomers was more vulnerable to reductive decomposition than the linear isomers for the higher electron affinity [41]. However, in our research, the photogenerated electron transited from the HOMOs to the LUMOs of GQDs, then influxed into the $\mathrm{CB}$ of $\mathrm{SiC}$ due to the matching energy levels between GQDs and $\mathrm{SiC}$, and finally transferred to the accumulated PFOS on the surface of SiC/GQDs. The final step resulted from the strong withdrawing property of the sulfonate group instead of high electron affinity of the $\mathrm{C}-\mathrm{F}$ bond, leading to the headgroup cleavage. Moreover, the $\mathrm{F}^{-}$detected in solution was much less 
than the $\mathrm{F}$ atom that bonded to the Si-terminations on SiC/GQDs, the main subsequent decomposition pathway of $\mathrm{C}_{\mathrm{n}} \mathrm{F}_{2 \mathrm{n}+1} \bullet$ can be thus ascribed to the hydrodefluorination process. These different mechanisms mentioned above, compared with the previous researches, led to the experimental phenomenon that the branched isomers decomposed at the similar kinetics with linear isomers.

\section{Conclusions}

The PFOS decomposition is of increasing concern due to its global distribution. This work demonstrated both branched and linear PFOS can be effectively decomposed with SiC/GQDs under $254 \mathrm{~nm}$ UV irradiation. The photogenerated electrons originated from the $\pi-\pi *$ transition of the $\mathrm{C}=\mathrm{C}$ bond and the $n-\pi^{*}$ transition of the $\mathrm{C}=\mathrm{O}$ bond, and then transferred from the LUMOs of GQDs to the conduction band (CB) of $\mathrm{SiC}$ nanoparticles due to heterojunction structure. PFOS transformed into $\mathrm{C}_{\mathrm{n}} \mathrm{F}_{2 \mathrm{n}+1} \bullet$ via the directional electron transfer from $\mathrm{SiC} / \mathrm{GQD}$ due to the high electronegativity of fluorine atoms, and subsequently further decomposed to short-chain PFCAs by the hydrolysis and hydrodefluorination. Results in the present study have the inspirational significance for research on PFCs decomposition in the aqueous environment. Further work is necessary to determine the toxicity of the decomposition products and the inactivation kinetics in the presence of dissolved organic matter (DOM, e.g. humic acid, fulvic acid) and other coexistent ions (e.g., $\mathrm{Cl}^{-}, \mathrm{NO}_{3}{ }^{-}, \mathrm{SO}_{4}{ }^{2-}$, $\mathrm{CO}_{3}{ }^{2-} / \mathrm{HCO}_{3}{ }^{-}$) to test the feasibility of this reaction system in natural or complex water matrix.

\section{Acknowledgments}

This study was financially supported by the National Science Foundation for Distinguished Young Scholars (No. 51625801), the National Natural Science Foundation of China (No. 51378065) and the Foundation for Innovative Research Group of the National Natural Science Foundation of China (No. 51421065). 


\section{References}

[1] United States Environmental Protection Agency, PFOA \& PFOS drinking water health advisories, 2016.

[2] M. Chen, L.W. Qiang, X.Y. Pan, S.H. Fang, Y.W. Han, L.Y. Zhu, In vivo and in vitro isomer-specific biotransformation of perfluorooctane sulfonamide in common carp (Cyprinus carpio), Environ. Sci. Technol. 49 (2015) 13817-13824.

[3] P. Zareitalabad, J. Siemens, M. Hamer, W. Amelung, Perfluorooctanoic acid (PFOA) and perfluorooctanesulfonic acid (PFOS) in surface waters, sediments, soils and wastewater - A review on concentrations and distribution coefficients, Chemosphere 91 (2013) 725-732.

[4] S.J. Liu, Y.L. Lu, S.W. Xie, T.Y. Wang, K.C. Jones, A.J. Sweetman, Exploring the fate, transport and risk of perfluorooctane sulfonate (PFOS) in a coastal region of China using a multimedia model, Environ. Int. 85 (2015) 15-26.

[5] C.A. Moody, G.N. Hebert, S.H. Strauss, J.A. Field, Occurrence and persistence of perfluorooctanesulfonate and other perfluorinated surfactants in groundwater at a fire-training area at Wurtsmith Air Force Base, Michigan, USA, J. Environ. Monit. 5 (2003) 341-345.

[6] C.A. Moody, J.W. Martin, W.C. Kwan, D.C. Muir, S.A. Mabury, Monitoring perfluorinated surfactants in biota and surface water samples following an accidental release of fire-fighting foam into Etobicoke Creek, Environ. Sci. Technol. 36 (2002) 545-551.

[7] S. Taniyasu, N. Yamashita, E. Yamazaki, G. Petrick, K. Kannan, The environmental photolysis of perfluorooctanesulfonate, perfluorooctanoate, and related fluorochemicals, Chemosphere 90 (2013) 1686-1692.

[8] G.H. Ding, L.Y. Wang, J. Zhang, Y.Y. Wei, L. Wei, Y. Li, M. H. Shao, D.Q. Xiong, Toxicity and DNA methylation changes induced by perfluorooctane sulfonate (PFOS) in sea urchin Glyptocidaris crenularis, Chemosphere 128 (2015) 225-230.

[9] T. Wang, Y.W. Wang, C.Y. Liao, Y.Q. Cai, G.B. Jiang, Perspectives on the inclusion of perfluorooctane sulfonate into the Stockholm Convention on persistent organic pollutants, Environ. Sci. Technol. 43 (2009) 5171-5175.

[10] K.L. Zhang, J. Huang, G. Yu, Q.W. Zhang, S.B. Deng, B. Wang, Destruction of perfluorooctane sulfonate (PFOS) and perfluorooctanoic acid (PFOA) by ball milling. Environ. Sci. Technol. 47 (2013) 6471-6477.

[11] H. Park, C.D. Vecitis, J. Cheng, W. Choi, B.T. Mader, M.R. Hoffmann, Reductive 
defluorination of aqueous perfluorinated alkyl surfactants: effects of ionic headgroup and chain length, J. Phys. Chem. A 113 (2009) 690-696.

[12] X.J. Lyu, W.W. Li, P.K. Lam, H.Q. Yu, Insights into perfluorooctane sulfonate photodegradation in a catalyst-free aqueous solution, Sci. Rep. 5 (2015) 9353.

[13] C.D. Vecitis, Y. Wang, J. Cheng, H. Park, B.T. Mader, M.R. Hoffmann, Sonochemical degradation of perfluorooctanesulfonate in aqueous film-forming foams, Environ. Sci. Technol. 44 (2009) 432-438.

[14] K.E. Carter, J. Farrell, Oxidative destruction of perfluorooctane sulfonate using boron-doped diamond film electrodes, Environ. Sci. Technol. 42 (2008) 6111-6115.

[15] Y.R. Gu, W.Y. Dong, C. Luo, T.Z. Liu, Efficient reductive decomposition of perfluorooctanesulfonate in a high photon flux UV/Sulfite system, Environ. Sci. Technol. 50 (2016) 10554-10561.

[16] H. Park, C.D. Vecitis, J. Cheng, N.F. Dalleska, B.T. Mader, M.R. Hoffmann, Reductive degradation of perfluoroalkyl compounds with aquated electrons generated from iodide photolysis at $254 \mathrm{~nm}$, Photochem. Photobiol. Sci. 10 (2011) 1945-1953.

[17] D.H. Huang, L.F. Yin, J.F. Niu, Photoinduced Hydrodefluorination Mechanisms of Perfluorooctanoic Acid by SiC/Graphene Catalyst, Environ. Sci. Technol. 50 (2016) $5857-5863$.

[18] P.V. Kamat, K. Tvrdy, D.R. Baker, J.G. Radich, Beyond photovoltaics: semiconductor nanoarchitectures for liquid-junction solar cells, Chem. Rev. 110 (2010) 6664-6688.

[19] H. Lee, H.C. Leventis, S.J. Moon, P. Chen, S. Ito, S.A. Haque, T. Torres, F. Nüesch, T. Geiger, S.M. Zakeeruddin, M. Grätzel, M.K. Nazeeruddin, PbS and CdS Quantum Dot-Sensitized Solid-State Solar Cells: "Old Concepts, New Results", Adv. Funct. Mater. 19 (2009) $2735-2742$.

[20] I.V. Lightcap, P.V. Kamat, Fortification of CdSe quantum dots with graphene oxide. Excited state interactions and light energy conversion, J. Am. Chem. Soc. 134 (2012) 7109-7116.

[21] X.M. Li, M.C. Rui, J.Z. Song, Z.H. Shen, H.B. Zeng, Carbon and graphene quantum dots for optoelectronic and energy devices: a review, Adv. Funct. Mater. 25 (2015) 4929-4947.

[22] C.K. Chua, Z. Sofer, P. Simek, O. Jankovský, K. Klímová, S. Bakardjieva, S. Hrdličková Kučková, M. Pumera, Synthesis of strongly fluorescent graphene quantum dots by 
cage-opening buckminsterfullerene, ACS Nano 9 (2015) 2548-2555.

[23] L. Jin, P.Y. Zhang, Photochemical decomposition of perfluorooctane sulfonate (PFOS) in an anoxic alkaline solution by 185nm vacuum ultraviolet, Chem. Eng. J. 280 (2015) 241-247.

[24] V. Ochoa-Herrera, R. Sierra-Alvarez, A. Somogyi, N. E. Jacobsen, V. H. Wysocki, J.A. Field, Reductive defluorination of perfluorooctane sulfonate, Environ. Sci. Technol. 42 (2008) 3260-3264.

[25] G. Arsenault, B. Chittim, J. Gu, A. McAlees, R. McCrindle, V. Robertson, Separation and fluorine nuclear magnetic resonance spectroscopic $\left({ }^{19} \mathrm{~F}\right.$ NMR) analysis of individual branched isomers present in technical perfluorooctanesulfonic acid (PFOS), Chemosphere 73 (2008) 53-59.

[26] L.L. Li, J. Ji, R. Fei, C.Z. Wang, Q. Lu, J.R. Zhang, L.P. Jiang, J.J. Zhu, A facile microwave avenue to electrochemiluminescent two-color graphene quantum dots, Adv. Funct. Mater. 22 (2012) 2971-2979.

[27] D. Qu, M. Zheng, P. Du, Y. Zhou, L.G. Zhang, D. Li, H.Q. Tan, Z. Zhao, Z. G. Xie, Z.C. Sun, Highly luminescent S, N co-doped graphene quantum dots with broad visible absorption bands for visible light photocatalysts, Nanoscale 5 (2013) 12272-12277.

[28] S.K. Cushing, M. Li, F.Q. Huang, N.Q. Wu, Origin of strong excitation wavelength dependent fluorescence of graphene oxide, ACS Nano 2013, 8, 1002-1013.

[29] J. Peng, W. Gao, B.K. Gupta, Z. Liu, R. Romero-Aburto, L.H. Ge, L. Song, L.B. Alemany, X.B. Zhan, G.H. Gao, S.A. Vithayathil, B.A. Kaipparettu, A.A. Marti, T. Hayashi, J. J. Zhu, P.M. Ajayan, Graphene quantum dots derived from carbon fibers, Nano lett. 12 (2012) 844-849.

[30] D.Y. Pan, J.C. Zhang, Z. Li, M.H. Wu, Hydrothermal route for cutting graphene sheets into blue-luminescent graphene quantum dots, Adv. Mater. 22 (2010) 734-738.

[31] R. Hoffmann, Trimethylene and the addition of methylene to ethylene, J. Am. Chem. Soc. 90 (1968) 1475-1485.

[32] Y.T. Dong, D.H. Son, Strongly nonlinear dependence of energy transfer rate on $\mathrm{sp}^{2}$ carbon content in reduced graphene oxide-quantum dot hybrid structures, J. Phys. Chem. Lett. 6 (2014) $44-47$.

[33] F. Liu, M.H. Jang, H.D. Ha, J.H. Kim, Y.H. Cho, T.S. Seo, Facile synthetic method for pristine graphene quantum dots and graphene oxide quantum dots: origin of blue and green 
luminescence, Adv. Mater. 25 (2013) 3657-3662.

[34] J. Hou, W. Wang, T.Y. Zhou, B. Wang, H.Y. Li, L. Ding, Synthesis and formation mechanistic investigation of nitrogen-doped carbon dots with high quantum yields and yellowish-green fluorescence, Nanoscale 8 (2016) 11185-11193.

[35] X. Zhang, F. Wang, H. Huang, H.T. Li, X. Han, Y. Liu, Z.H. Kang, Carbon quantum dot sensitized $\mathrm{TiO} 2$ nanotube arrays for photoelectrochemical hydrogen generation under visible light, Nanoscale 5 (2013) 2274-2278.

[36] S.L. Hu, W.Y. Zhang, Q. Chang, J.L. Yang, K. Lin, A chemical method for identifying the photocatalytic active sites on carbon dots, Carbon 103 (2016) 391-393.

[37] J. Liu, Y. Liu, N. Y. Liu, Y. Z. Han, X. Zhang, H. Huang, Y. Lifshitz, S.T. Lee, J. Zhong, Z.H. Kang, Metal-free efficient photocatalyst for stable visible water splitting via a two-electron pathway. Science 347 (2015) 970-974.

[38] Z.F. Zhu, S.D. Wang, Y.J. Chang, D.B. Yu, Y. Jiang, Direct photodissociation of toluene molecules to photoluminescent carbon dots under pulsed laser irradiation, Carbon 105 (2016) 416-423.

[39] F.E. Osterloh, Inorganic nanostructures for photoelectrochemical and photocatalytic water splitting. Chem. Soc. Rev. 42 (2013) 2294-2320.

[40] H. Hori, E. Hayakawa, H. Einaga, S. Kutsuna, K. Koike, T. Ibusuki, H. Kiatagawa, R. Arakawa, Decomposition of environmentally persistent perfluorooctanoic acid in water by photochemical approaches, Environ. Sci. Technol. 38 (2004) 6118-612440[41]

[41] A. Paul, C.S. Wannere, H.F. Schaefer, Do linear-chain perfluoroalkanes bind an electron? The J. Phys. Chem. A 108 (2004) 9428-9434. 
Table 1 Decomposition kinetics and the electrical energy per order parameter (EEO) of technical-PFOS

\begin{tabular}{ccccccc}
\hline No. & Technical-PFOS & $\begin{array}{c}\text { Decomposition } \\
\text { ratios }(\%)\end{array}$ & $\begin{array}{c}\text { Decomposition } \\
\text { rate constants } \\
\left(\boldsymbol{k}, \mathrm{h}^{-1}\right)\end{array}$ & $\begin{array}{c}\text { Half-lives } \\
(\mathrm{h})\end{array}$ & $R^{2}$ & $\begin{array}{c}E E O^{\mathrm{b}} \\
\left(\mathrm{kWh} / \mathrm{m}^{3} / \mathrm{orde}\right.\end{array}$ \\
\hline 1 & linear-PFOS & 88.5 & 0.098 & 7.1 & 0.98 & 1.47 \\
2 & $2-\mathrm{CF}_{3}$-PFOS & 93.9 & 0.127 & 5.5 & 0.99 & 1.13 \\
3 & $6-\mathrm{CF}_{3}$-PFOS & 90.4 & 0.115 & 6.0 & 0.99 & 1.25 \\
\hline
\end{tabular}

${ }^{\mathrm{a}}$ The initial concentration of technical-PFOS is $0.019 \mathrm{~mol} \mathrm{~L}^{-1}$.

${ }^{b}$ The electrical energy per order parameter, defined as the number of kilowatt-hours (kWh) of electrical energy required to reduce the concentration of a pollutant by one order of magnitude (90\%) in $1 \mathrm{~m}^{3}$ contaminated water, adopted by the International Union of Pure and Applied Chemistry (IUPAC). 


\section{Figure Captions}

Figure 1. Pseudo-first-order kinetic plots of PFOS $\left(0.019 \mathrm{mmol} \mathrm{L}^{-1}\right)$ under $254 \mathrm{~nm} \mathrm{UV} \mathrm{light}$ irradiation in the presence of SiC/GQDs $\left(0.5 \mathrm{~g} \mathrm{~L}^{-1}\right)$ at room temperature $\left(25 \pm 1{ }^{\circ} \mathrm{C}\right)$, and the $\mathrm{pH}$ value was 7: (a) decomposition rates of $2-\mathrm{CF}_{3}$-PFOS isomers, (b) decomposition rates of $6-\mathrm{CF}_{3}$-PFOS isomers, (c) decomposition rates of Linear-PFOS isomers.

Figure 2. (a) Multiple reaction monitoring (MRM) results of PFOS detected by triple-stage quadrupole mass spectrometry (TQ-MS/MS) at room temperature $\left(25 \pm 1{ }^{\circ} \mathrm{C}\right)$. These short-chain perfluorocarboxylic acids (PFCAs) including $\mathrm{C}_{3} \mathrm{~F}_{7} \mathrm{COO}^{-}(\mathrm{PFBA}), \mathrm{C}_{4} \mathrm{~F}_{9} \mathrm{COO}^{-}$ (PFPeA), $\mathrm{C}_{5} \mathrm{~F}_{11} \mathrm{COO}^{-}(\mathrm{PFHxA}), \mathrm{C}_{6} \mathrm{~F}_{13} \mathrm{COO}^{-}(\mathrm{PFHpA})$ and $\mathrm{C}_{7} \mathrm{~F}_{15} \mathrm{COO}^{-}$(PFOA) were detected during the decomposition process at 1.99, 2.36, 2.95, 3.76, $4.64 \mathrm{~min}$, respectively; (b) the concentration variations of intermediates, as a function of decomposition time.

Figure 3. Mass balance of fluorine element and sulfur element during the decomposition process at room temperature $\left(25 \pm 1{ }^{\circ} \mathrm{C}\right)$. The dosage of SiC/GQDs was $0.5 \mathrm{~g} \mathrm{~L}^{-1}$, the wavelength of UV light was $254 \mathrm{~nm}$, the $\mathrm{pH}$ value was 7, and the concentration of PFOS was 0.019 $\mathrm{mmol} \mathrm{L}{ }^{-1}$.

Figure 4. Characterization of the optical properties of the graphene quantum dots (GQDs): (a) UV-vis absorption spectra of GQDs, (b) fluorescence emission-excitation map of the GQDs at different excitation wavelengths. GQDs were dispersed in water, and the experiments were performed at room temperature $\left(25 \pm 1^{\circ} \mathrm{C}\right)$.

Figure 5. Characterization of the electrical properties of the SiC/GQDs: (a) X-ray photoelectron spectroscopy (XPS) results of C-1s region high-resolution spectra of SiC/GQDs at room temperature $\left(25 \pm 1{ }^{\circ} \mathrm{C}\right)$, (b) ultraviolet photoelectron spectroscopy (UPS) spectra of SiC and as-synthesized SiC/GQDs at room temperature $\left(25 \pm 1{ }^{\circ} \mathrm{C}\right)$. The dashed black lines mark the baseline and the dashed red lines indicate the tangents of the curve. The valence 
band energy $(E v)$ can be calculated from the intersections of the tangents with the baseline,

(c) typical transfer of electrons and holes in the SiC/GQDs heterojunction structure under UV light excitation.

Figure 6. Decomposition mechanisms of PFOS with SiC/graphene at room temperature $\left(25 \pm 1^{\circ} \mathrm{C}\right)$. The dosage of SiC/GQDs was $0.5 \mathrm{~g} \mathrm{~L}^{-1}$, the wavelength of UV light was $254 \mathrm{~nm}$, the $\mathrm{pH}$ value was 7 , and the concentration of PFOS was $0.019 \mathrm{mmol} \mathrm{L}^{-1}$. 

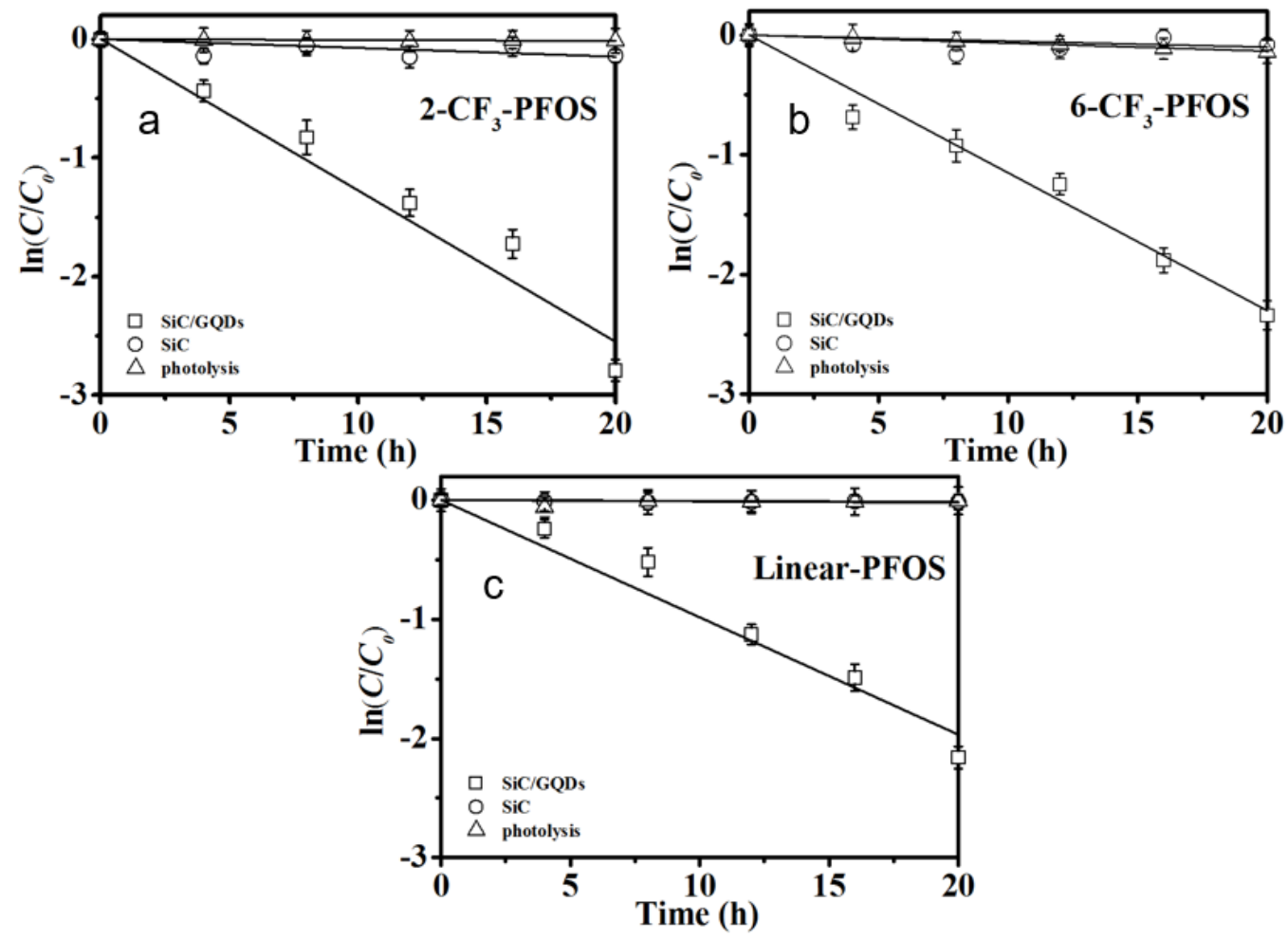

Figure 1. Pseudo-first-order kinetic plots of PFOS $\left(0.019 \mathrm{mmol} \mathrm{L}^{-1}\right)$ under $254 \mathrm{~nm} \mathrm{UV} \mathrm{light}$ irradiation in the presence of SiC/GQDs $\left(0.5 \mathrm{~g} \mathrm{~L}^{-1}\right)$ at room temperature $\left(25 \pm 1^{\circ} \mathrm{C}\right)$, and the $\mathrm{pH}$ value was 7: (a) degradation rates of 2-CF $-\mathrm{PFOS}$ isomers, (b) decomposition rates of 6- $\mathrm{CF}_{3}-\mathrm{PFOS}$ isomers, (c) decomposition rates of Linear-PFOS isomers. 

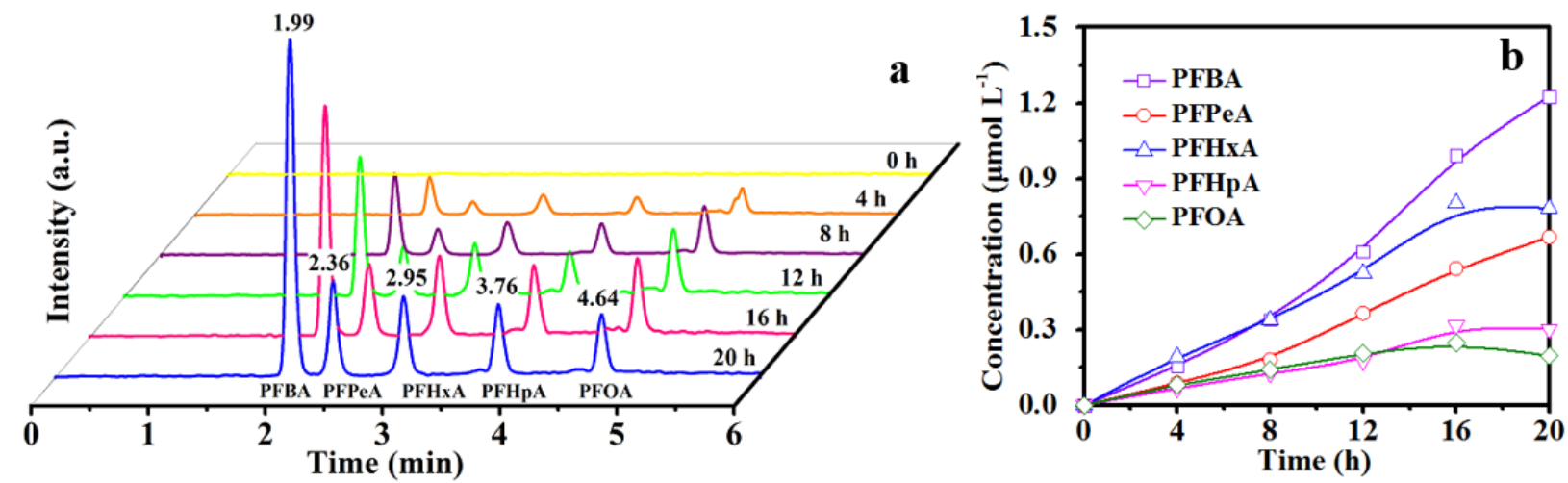

Figure 2. (a) Multiple reaction monitoring (MRM) results of intermediates detected by triple-stage quadrupole mass spectrometry (TQ-MS/MS) at room temperature $\left(25 \pm 1{ }^{\circ} \mathrm{C}\right)$. These short-chain perfluorocarboxylic acids (PFCAs) including $\mathrm{C}_{3} \mathrm{~F}_{7} \mathrm{COO}^{-}$(PFBA), $\mathrm{C}_{4} \mathrm{~F}_{9} \mathrm{COO}^{-}(\mathrm{PFPeA}), \mathrm{C}_{5} \mathrm{~F}_{11} \mathrm{COO}^{-}$ (PFHxA), $\mathrm{C}_{6} \mathrm{~F}_{13} \mathrm{COO}^{-}(\mathrm{PFHpA})$ and $\mathrm{C}_{7} \mathrm{~F}_{15} \mathrm{COO}^{-}(\mathrm{PFOA})$ were detected during the decomposition process at 1.99, 2.36, 2.95, 3.76, $4.64 \mathrm{~min}$, respectively; (b) the concentration variations of intermediates, as a function of decomposition time. 


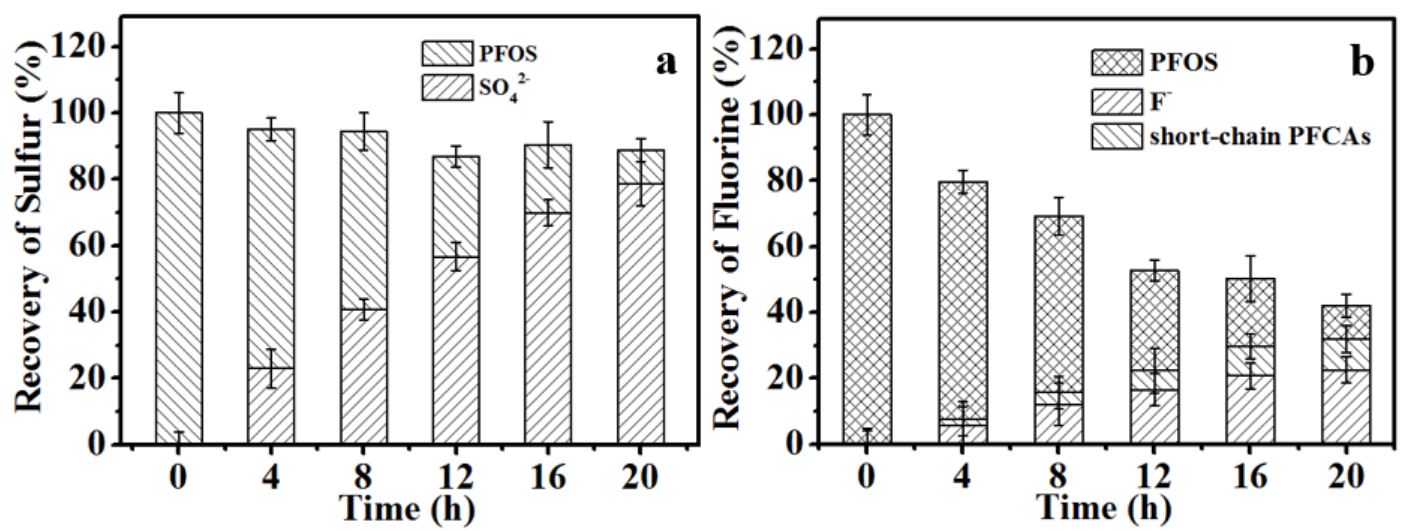

Figure 3. Mass balance of sulfur element and fluorine element during the decomposition process at room temperature $\left(25 \pm 1{ }^{\circ} \mathrm{C}\right)$. The dosage of SiC/GQDs was $0.5 \mathrm{~g} \mathrm{~L}^{-1}$, the wavelength of UV light was $254 \mathrm{~nm}$, the $\mathrm{pH}$ value was 7, and the concentration of PFOS was $0.019 \mathrm{mmol} \mathrm{L}^{-1}$. 


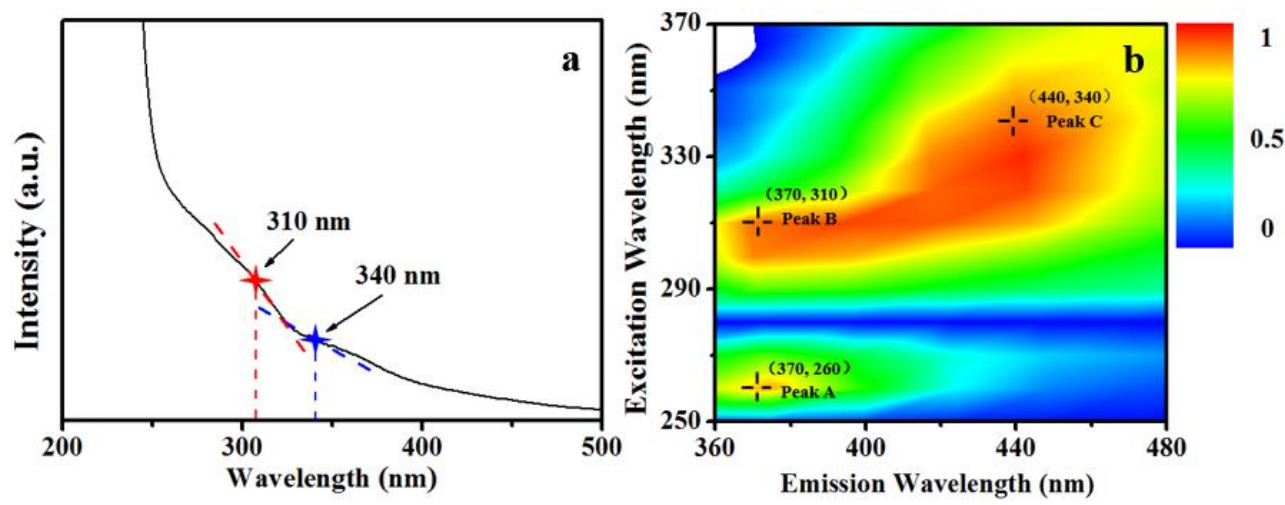

Figure 4. Characterization of the optical properties of the graphene quantum dots (GQDs): (a) UV-vis absorption spectra of GQDs, (b) fluorescence emission-excitation map of the GQDs at different excitation wavelengths. GQDs were dispersed in water, and the experiments were performed at room temperature $\left(25 \pm 1^{\circ} \mathrm{C}\right)$. 

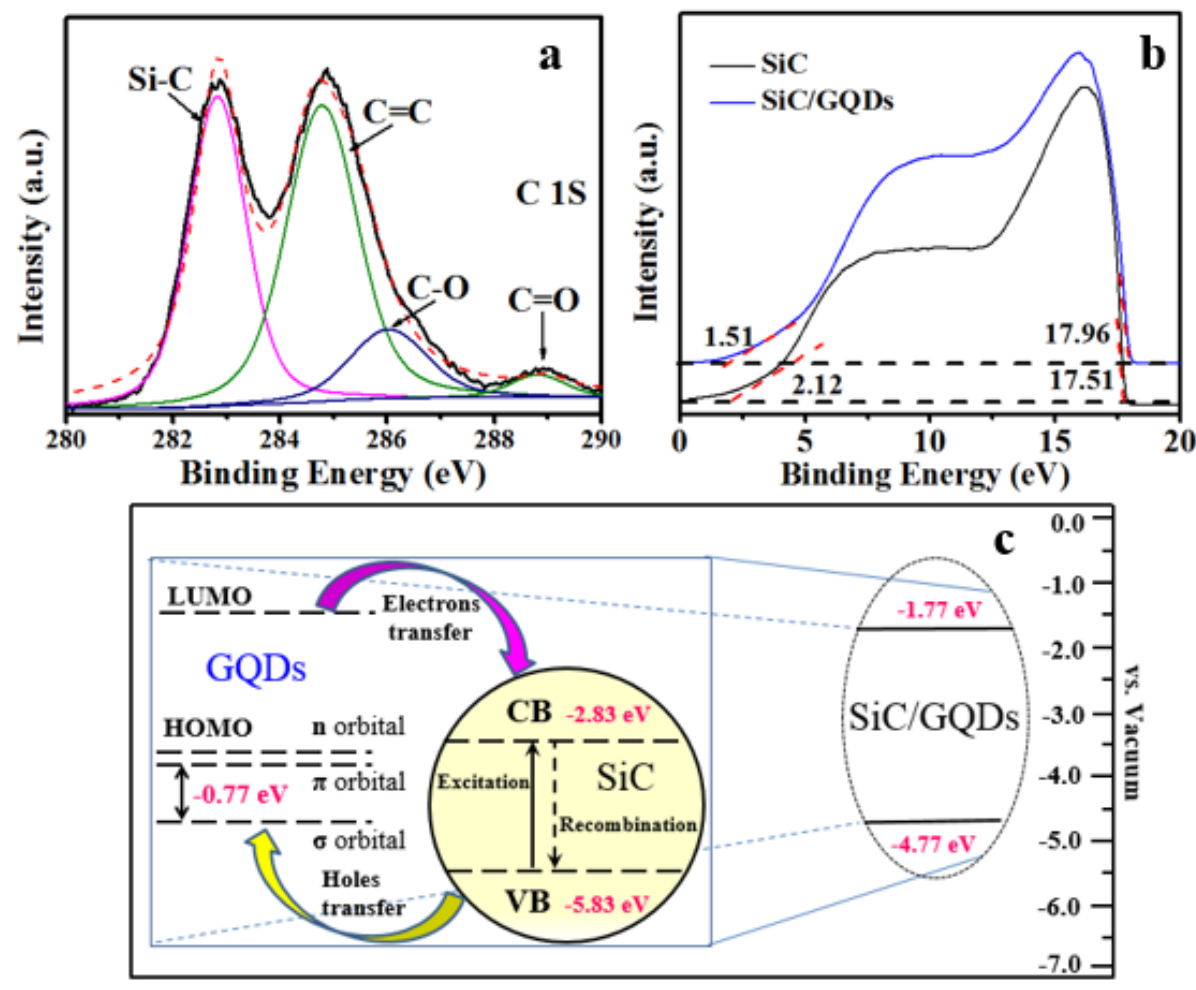

Figure 5. Characterization of the electrical properties of the SiC/GQDs: (a) X-ray photoelectron spectroscopy (XPS) results of C-1s region high-resolution spectra of SiC/GQDs at room temperature, (b) ultraviolet photoelectron spectroscopy (UPS) spectra of SiC and as-synthesized SiC/GQDs at room temperature $\left(25 \pm 1{ }^{\circ} \mathrm{C}\right)$. The dashed black lines mark the baseline and the dashed red lines indicate the tangents of the curve. The valence band energy $(E v)$ can be calculated from the intersections of the tangents with the baseline, (c) typical transfer of electrons and holes in the SiC/GQDs heterojunction structure under UV light excitation. 

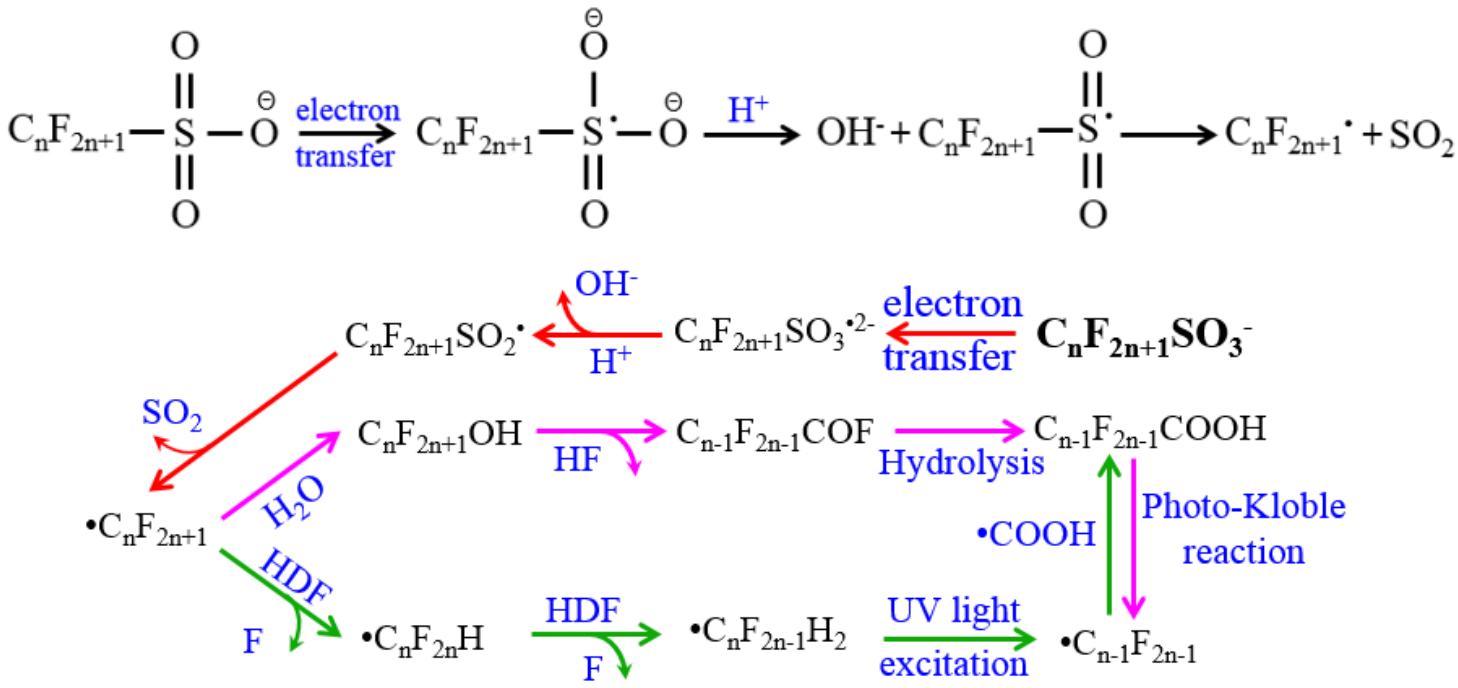

Figure 6. Decomposition mechanisms of $\mathrm{PFOS}$ with $\mathrm{SiC} /$ graphene at room temperature $\left(25 \pm 1{ }^{\circ} \mathrm{C}\right)$. The dosage of SiC/GQDs was $0.5 \mathrm{~g} \mathrm{~L}^{-1}$, the wavelength of UV light was $254 \mathrm{~nm}$, the $\mathrm{pH}$ value was 7, and the concentration of PFOS was 0.019 mmol L $\mathrm{L}^{-1}$. 


\section{Graphical Abstract}

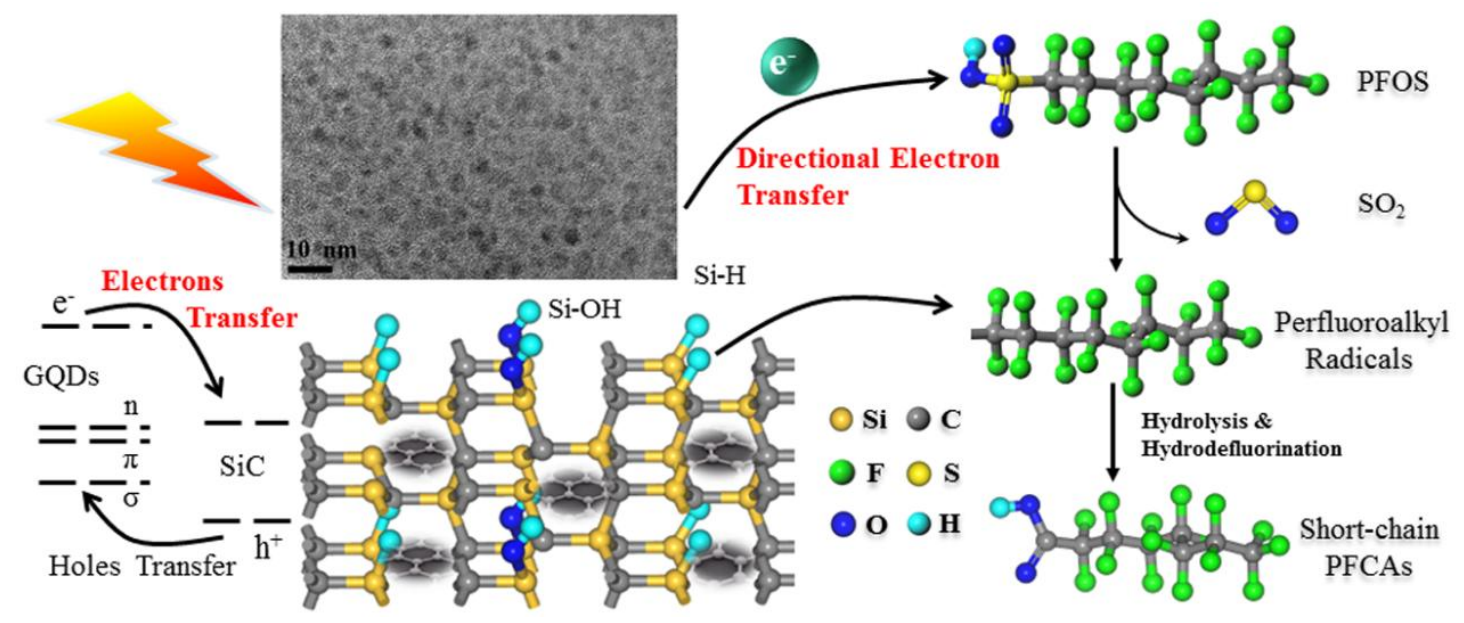

